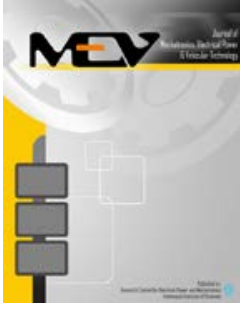

Journal of Mechatronics, Electrical Power, and Vehicular Technology

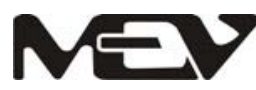

\title{
A study on the applicability of batik for public transportation design in Indonesia
}

\author{
Yukhi Mustaqim Kusuma Sya' bana ${ }^{\mathrm{a}, *}$, Gun Bae Park ${ }^{\mathrm{b}}$ \\ ${ }^{a}$ Research Centre for Electrical Power and Mechatronics, Indonesian Institute of Sciences (LIPI) \\ Komplek LIPI Jl. Sangkuriang, Building 20, Bandung 40135, Indonesia \\ ${ }^{b}$ Industrial Design Laboratory, Art and Design Faculty, Keimyung University \\ 104 Myeongdeok-ro, Daemyeong 3(sam)-dong, \\ Nam-gu, Daegu, 42403, Republic of Korea
}

Received 25 July 2020; Accepted 3 November 2020; Published online 22 December 2020

\begin{abstract}
This paper attempts to grant Indonesian identity in the development and importing the public transportation equipment from overseas. We reviewed and surveyed the present state issues of Indonesian public transportation equipment design development. The study analyzed the philosophical values of batik in a modern way, the possibility of Batik application for important regionalism identity, and identity in design development strategy. As a result, we gather and assess the philosophical values of Batik motifs that contain geographic origin, the essences, and characteristics to be applied as design element strategies. We found the regional identity of the historical, local wisdom essence, acculturation, various colors, and original shapes of the Batik motifs. Moreover, Indonesian fancy design is also supported by other possibilities indigenous material and technique that usually used, particularly in Indonesia. These possibilities were identically Indonesian and also applicable as the sustainable public transport equipment design identity issue solution. This effort was conducted as the turning point to solve the issues of public transport equipment design strategies dependency. Thus, this research will be helpful for aesthetics research in the modern way of the public transportation equipment design concept.
\end{abstract}

(C2020 Research Center for Electrical Power and Mechatronics - Indonesian Institute of Sciences. This is an open access article under the CC BY-NC-SA license (https://creativecommons.org/licenses/by-nc-sa/4.0/).

Keywords: batik philosophical values; public transportation equipment; national identity; vernacular design.

\section{Introduction}

The transportation growth index was followed by congestion issues in Indonesia. This situation was strongly related to the number of private vehicle usage, public transport equipment services satisfaction [1], road development growth, population, and urbanization. After postponed more than 20 years regarding the economic crisis issues, the mega project mass rapid transit (MRT) and bus rapid transit (BRT) finally started in 2013. Policies and road arrangement strategy also conducted to reduce congestion in Indonesia, particularly Jakarta as the Indonesia capital city [2].

Three pillars of transport solution concepts are developing public transportation systems, developing land transportation infrastructures, and managing traffic and transportation demands [3].

\footnotetext{
${ }^{*}$ Corresponding Author. Tel: +62-222503055; Fax: +62-222504773 E-mail address: yukh001@lipi.go.id
}

Thus the high demand for using private vehicles will reduce people's interest in using public transport in Indonesia. These conditions assumed will affect the economic, social, and environmental aspects of the city.

Indonesia is the second biggest automotive manufacturing industry, following Thailand in ASEAN. This country has an important role in many automotive brands' investment, especially in manufacturing hubs, to produce vehicles for export in Asia and beyond. In the recent situation, Indonesia has a large population and also rapid growth of the middle class. It also generates domestic market size for car sales above one million cars a year in 2016 [4] Local private industries or State-owned Legal Entities in Indonesia were capable of producing public transport and equipment, e.g. ship, railway coach, aircraft, bus, light rail transit (LRT), metro capsule, and monorail. These abilities are mostly made domestically; the scope consists of covering components, support services, fabrication services, 
installation services, engineering services, design, and maintenance with a limited scale.

Public transportation equipment development purposed to fulfill daily mobility commuter, leisure, and tourism public transport provision. Attractive public transportation equipment demand plays an important role in design decisions to support new experiences of commuting, satisfaction, and quality. Recently, primary transport development still depends on the overseas manufacturer brands due to their competencies, as seen in Figure 1.

Providing local identity to become a national identity in public transport equipment is considered important to solve the design development issue. Identity has a different level from national identity, regional identity, urban identity, and local identity [5]. While local identity should provide distinctive physical, social, historical, and aesthetic. At this time, was a lack of local design requirements role in the procurement of transportation facilities. A distinctive of local user behavior, identity, dimension, features, design sense, cultural promotion, these should be well designed by a local designer. Considering the representation of local identity gives an innovative exploration spirit of the design era. It is intended to represent the character of the Indonesian nation that distinguishes from other countries and raises the dignity aspect. Moreover, dignity is a sense of pride in oneself, the state or quality of being worthy of honor or self-respect. A study stated the dignity of identity allows feelings of self-respect and pride and then became a critical component of workers' experience, especially in tourism [6]. The movement of local design identity applicability could be a trigger for another product, user experience, and designers in order to supports governments and local industries. It should start soon to get independent industrialization that will generate social, environmental, and economic welfare growth in the country. Today, a creative economy involving a local identity is incision from sustainability, innovation, cultural diversity, and social inclusion [7][8]. For instance, the tourism industry in Indonesia will relate with design as an innovation aspect, job opportunities as social inclusion aspect, preservation as cultural diversity aspect, and sustainability aspect.

The recent situation has an issue to design indigenous culture strategy with wisely application, thus this paper attempts to confer Indonesian national identity on public transport equipment development to be expensive, elegant, and fancy design. Cultural preservation and create a niche

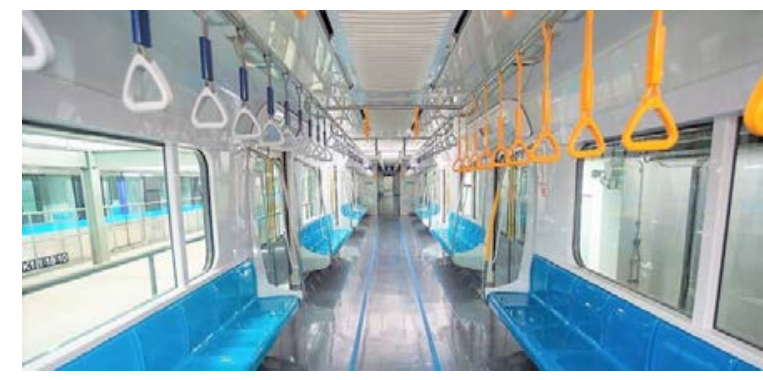

Figure 1. The interior design of Jakarta mass rapid transit (MRT) is designed and produced by Sumitomo Corporation Japan market in transportation design is an opportunity to compete with foreign producers. This main study objective is to contribute relevant possibilities of reinterpretation vernacular Indonesian Batik concept onto the public transport design as seen in Figure 2. Mind mapping was conducted on the recent status of road public transportation development in Indonesia. We highlighted the crucial keywords to be discussed in this paper, including national identity, local design strategy, culture, preservation, social innovation, applicability, and vernacular design.

The one of vernacular design that was designed based on indigenous was called Batik. The applicability, application possibility, or usefulness can be achieved by observing the design trends and the history of Batik. This Indonesian culture motif assumed has a lot of values that reflected the characteristics, identity, intrinsic philosophical meaning, and communication media in each of the regional motifs. The implied means of the local wisdom motifs, colors, and patterns were affected by the beginning of the acculturation religion era, ancient kingdom, trade activities, agricultural, colonialism, and local region cultures in the past [9]. In 2009, the united nations educational, scientific, and cultural organization (UNESCO) had accepted, and the Indonesian government has officially declared Batik as the national heritage of indigenous Indonesian culture. The Indonesian government had defined for celebrating Batik national day every $2^{\text {nd }}$ of October to celebrate when UNESCO recognized Batik in 2009. The student and workers appealed to use Batik every Friday and, followed by civil servant minister of home affairs, established the rules in 2015. These current situations assumed Batik take an important role as the national cultural identity of Indonesian heritage.

Indonesia has over 13.000 islands with more than 720 languages, and 640 were recorded by UNESCO as well as there were 5.300 indigenous foods, and it was recorded motifs of Batik unless a total of 5.489 and recently still counting [10]. Pride in using Batik as national identity impacted these motifs as embracing heterogeneous multiculturalism in Indonesia.

Batik has amazed the world not as a souvenir and fabrics yet as artwork and elegant design from Indonesia due to the values and life philosophy. Handcrafting Batik is unique and has a distinctive wax-resist dyeing process and coloring method. The waxing process of resisting the colors use a special tool called canting followed by coloring with dyeing technique, removing the wax with boil water, and repeating waxing intended for multiplying colors. However, the implementation of Batik mainly applied to fashion and fabric media.

Batik motifs and processes were preserved and adaptable in each era. It was hereditary and depending on the demands and needs of the particular social community at the time. The contemporary sustainable Batik has a wise value with using natural dye colors from eco-friendly plants and fruits; recycling used wax, natural drying rely upon the weather, electric smokeless wax 


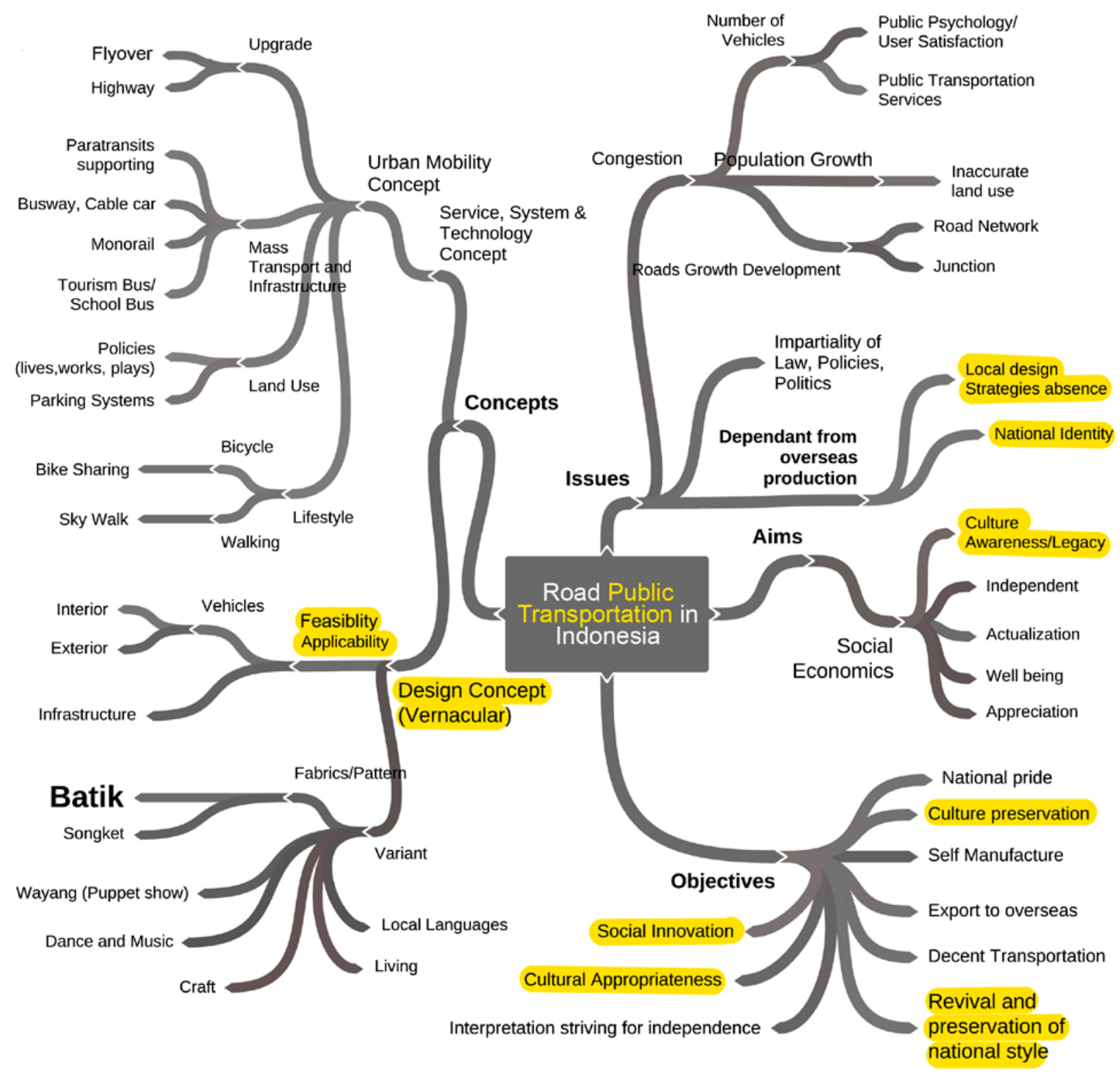

Figure 2. Mind mapping status and direction of road public transportation equipment in Indonesia

heating stove, etc. Contemporary motif and support of appropriate technology generate Batik to become affordable items to all circles.

Hereditary factors (e.g., material, production method, technology, climate, region, and socialculture) were causing Batik as the vernacular design of Indonesia [11][12]. However, we assume it needs to improve the design methods and other applicability to be accepted, as seen in Figure 3 . Mind mapping was conducted to extract and pursing the recent status of Batik as vernacular design in Indonesia. We highlighted the main study by applicability/feasibility, values/essence, and the art and design approach. In this paper, we shall argue the relationship and possibilities between vernaculars Batik with the public transportation equipment design principles method approach.

\section{Materials and Methods}

The attempt applicability of national identity to a fancy design strategy public transportation can be achieved in various ways. "Three-levels of the emotional design" and culture level was applied to reinforce acceptance of the human-centered design [13]. The outer level is visceral design or tangible level related to appearance, form, color, line, texture, detail, physical, and material. Secondly, mid-level or behavioral design related to function, usability, operation, safety, and user pleasure. Lastly, the inner level or a reflective design related to self-image, affection, and cultural features. We selected art and design approach methods to cover the cultural level/emotional of Batik, including kitsch, metaphor, affordance design, sustainable design, eco-design, appropriate technology design, and recycle. 


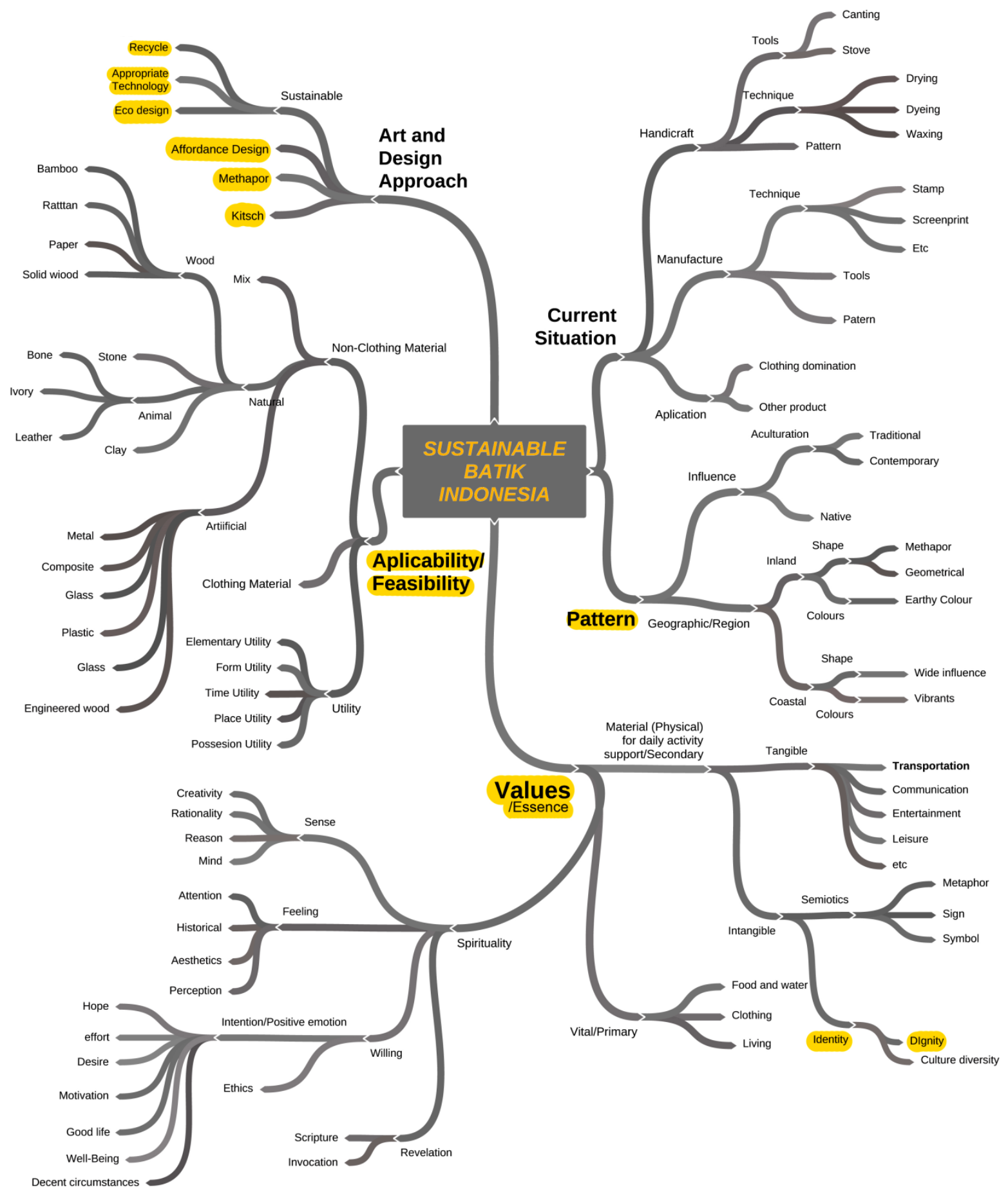

Figure 3. Mind mapping sustainable Batik as Indonesian vernacular design

A. Design principles of vernacular Batik and sustainable public transportation equipment

Vernacular is a term that is often used for linguistic and architectural, refers to indigenous or related to local distinctive and contextual philosophy, whether explicit or implicit in the population region. The vernacular model is divided into traditional and modern/contemporary vernacular [14][15], developed along with hereditary factors (i.e., material, production method, technology, climate, region, and social-culture). Indigenous reinterpretation characterized by styles, morphological elements, and development techniques, in order achieved through a system of shared rules in their inhabitants. Moreover, distinctive regional conservation took an important role in the local distinctiveness [16][17]. As such, regionalism with distinctive geography emphasizes optimizing the environment-behavior interaction as a consideration of sustainable vernacular design. As time goes by, a distinctive pattern changed, and man's development and achievements are affected by resources and technology in the past, present, and future. 


\section{B. Kitsch}

The word 'kitsch' comes from Germany and was used in 1925 for images of 'cheap'. By imitating noble behaviors and habits into daily, an imitation or aesthetic pantomime that is usually associated with an attempt to show the people's social status [18][19]. This industrial culture phenomenon generates art positioned as a creation that is controlled by market needs [20][21]. Thus, the vernacular art handmade reinterpretation will become kitsch with contemporary material and mass production techniques as today's daily application.

In history, Batik was and sacred clothing; no one wears them except the palace family [22][23]. Indeed, at that time, Batik not merely as a decoration or royal ornaments itself yet became an appliance to held ritual of the kingdom. Batik was turned out to be the trigger of the social gap between the nobles with the indigenous people. The art of Batik was dominance by the nobility and later, Batik almost became a media of breaking the tough conflicts. However, as time goes by, this gap disappears, and almost everybody uses it. Generated by developments of the production technique, the special craftsmen technique of waxing with special tools called canting was replaced with modern coloring, printing, drawing, stamping, etc. The process of manual waxing Batik with natural colors also takes a long time regarding the coloring processes are repeatedly. As a result, traditional Batik prices are sold more expensive per sheet compared with the modern production method.

\section{Sustainable design}

Sustainable Batik development is how to improve the environment by compromising economic and social factors. The three main pillars (economic, social, and environmental) are interdependent and reinforcing [24].

Sustainable development is linked to economic growth and how to find ways to advance the economy over the long term, without depleting natural capital. Resources on the earth are limited; thus this effort was to fulfill today' s needs without sacrificing future generations. Cultural diversity, in this case Batik is important for sustainable development policy as well as the importance of biodiversity to intellectual, emotional, moral, and spiritual.

\section{Eco design}

Eco-design, design for sustainability, or green design is a product designing approach with considering environmental effects. It involves optimizing the entire life-cycle of each product from the design phase to production, consumption, and disposal. Vernacular using local raw materials are more economical, reduces the costs of shipping, fuel consumption, and $\mathrm{CO}_{2}$ emissions produced from transportation and mobility. Household and industrial deliver large contribution of river waste that exacerbates pollution generate environmental damage in general. Clean production and utilize appropriate technology concepts need to initiate to produce sustainable Batik.

Chemical-based coloring agent manufacturing will generate waste and pollution. In contrast, some examples of natural colors that eco Batik used were brown color from coconut fiber or tea leaves, yellowish red color from cinnamon, yellow color from turmeric, blue color from indigo leaves, and reddish-brown from mango peels. Batik natural dyes coloring material is using parts of plants, such as leaves, skin, stems, seeds, fruits, and flowers [25][26] This includes safe waste management, in which all Batik production waste would be first processed and wasteless for the rivers. Among the initiatives proposed in this stage includes the acceleration of the reforestation movement by cultivating forests of natural dye-producing plants. Besides, using environmentally friendly technologies such as the Batik process is using natural dyes generates a soft color than chemical dyes.

\section{E. Recycle}

Several raw materials used for products are recyclable to be another valuable new object that requires energy to process [27][28]. At the end of the life-cycle, waste should be reduced or reused intact items as a diminishing impact on the environment [29][30]. Consideration of recycling in the designing process involving manufacture, assembly, and material processing [31][32][33]. Waste of wax also can be reused and recycle to emphasize the production costs as applied in some small industries of Batik. Moreover, using natural dyes without damaging the growing plants are possible to conduct. Recycle natural waste from household and furniture industries such as plants, fruits skin, wood skin, wood waste, etc. As an example, the city that produced Batik, such as Cirebon, has many furniture industries and produces waste of wood shavings. In Pekalongan city, many supermarkets are throwing rotten fruit that the potential to conduct recycling. Patchwork scraps of Batik also applicable to be a recycled aesthetics element of artworks or mix media of contemporary paintings and generate new values either economics or aesthetics.

\section{F. Appropriate technology design}

Commonly known as choice of technology within the application were decentralized characteristic, labor-intensive, small-scale, low energy used, and related to the local condition. Generally, appropriate technology adapted to the environmental, ethnic, cultural, social, political, and economic aspects of the community concerned. Appropriate technology is usually applied to describe simple technologies that are emphasized to the user that suitable for developing countries or else underdeveloped rural areas in industrialized countries [34][35].

Batik is made from natural dyes parts of plants, such as leaves, skin, stems, seeds, fruits, and flowers to make the production methods environmentally friendly and add more quality values. It possible to adapting intermediate technology in the community; however only those technologies have found acceptance in those mentioned aspects 
conditions prevailing in the developing country [36]. The vernacular concept needs appropriate technology design that will accept regionalism and improve the quality of life. Starting from coloring to drying, the production of Batik uses a material provided by nature. Various advantages are ranging from resistance to acid (sweat), resistance to fade, and heat. In addition, the brilliance of the resulting colors is also more durable and stable. Appropriate technology in Batik production, for example with an electric stove, will have significant savings compared to oil base and gas stove. The absence of firewood burning in the eco Batik method also does not produce smoke and no burning charcoal for perfect combustion as environmentally friendly. It also uses a blower to dissolve the remainder of the candle more efficiently, usually ineffective with a fuel base burning method. The room lighting also applied solar plastic bottle lamps that use only bottles of soft drink filled with chlorine and given water. The bottle is placed on the roof and instantly produces a glow of light equivalent to 55 watts that generate energy efficiency and cost. The last stage is the drying process, which is depending on the wind and the weather. Usually, it would take a long time depends on nature. Lastly, the oven/heating process obviously will make the candle/wax melting.

\section{G. Affordance design}

Quality of an object that allows an individual to perform an action, in short, the physical properties of an object should suggest how it should be used. Interaction between humans and products involving Visual (how it should be used), perceived (how it might be used), perceptual (five senses), and functional (design quality, effectiveness, usefulness) [37][38]. The tangibility of the meaning in the vernacular concept assumed determines an affordance quality on the application [39][40]. The special tools for making Batik called "canting", the term was from the Javanese language. The tool used to move or take the hot wax liquid and write into the fabrics to generate Batik. Traditional canting for Batik is a small tool made of copper and bamboo as a handle. It contains gagang, nyamplung, and cucuk. As the intuitive behavior like a pen to writing in the media, gagang or canting handle generally made of bamboo or wood. Another part called nyamplung that is a container for taking hot wax fluids in the iron skillet above the stove and it' s made of copper. Lastly, cucuk that is connected with nyamplung that shaped like a curve pipe has a function to drain the wax from nyamplung to scratch into the fabric, as shown in Figure 4.

\section{H. Metaphor design}

Etymologically it was defined as the use of words rather than the real meaning, for rhetorical effect and comparison. The metaphor method used to identify, frame, and to solve design problems aims to enhance product meaningfulness and appeal. The metaphors underlie how people think, reason, and imagine in everyday life in case tangible, intangible, or combined. The metaphor technique and simplification method resulted in superior memory

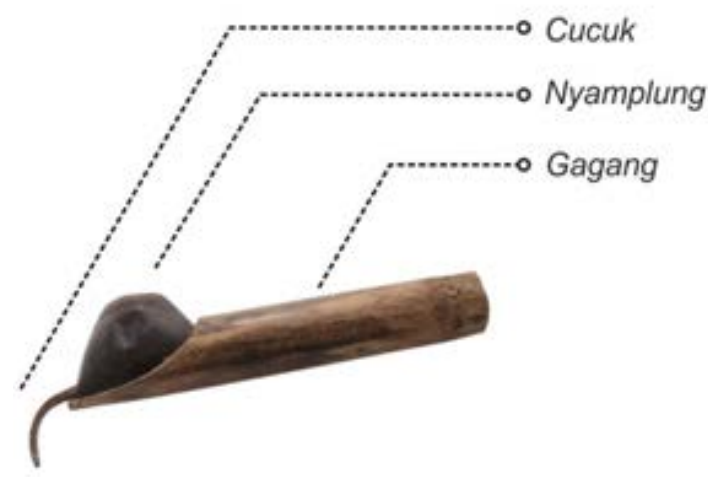

Figure 4. Affordance design of canting or the Batik coloring pen

and identification of an interaction between human and design interaction [41]. The feasibility of metaphor design as an affordance design in the vernacular aspect should be investigated to a better quality of usability design [42][43]. The wide diversity of Batik patterns reflects a variety of metaphor influences, ranging from Arabic calligraphy, European bouquets, and Chinese phoenixes to Japanese cherry blossoms and Indian or Persian peacocks.

\section{Results and Discussions}

\section{A. Design value and applicability of Batik}

Batik is mostly recognized as a unique process in making fabrics with distinctive motives and fashion applications. Batik variances and applications are dynamic and adaptable in the past, present, and future for all ages. Recently Batik also used in various media as an aesthetic element of decorating, household accessories, and fashion development. A glance at recent Indonesian public transportation development feasibility, will reflect decent circumstances, national characteristics, and identify the cultural diversity of particular social groups in Indonesia. Batik' s applicability to public transport necessary for design identity strategy, considering that every motif of Batik has different symbolic meaning values as independent local design movement. Recently the waning of authentic Batik is gripping; furthermore, necessary to figure out the essence of motifs to apply for various media in public transportation equipment. Batik as strategy and suggestion in design briefed narrowed by several keywords. We highlighted mind mapping, including vernacular design, design concept, applicability, identity, pattern, essence to be applied in public transportation equipment design, as seen in Figure 5.

Generally, Batik that was established from Javanese culture was divided into inland and coastal type. Inland (keraton) Batik has earthy colors, geometric shapes, elements, and is made from natural coloring textile dyes. On the contrary, coastal (pesisir) Batik has vibrant colors, non-geometric (organics) shape, natural motifs, and influenced by wide acculturation of maritime and trading culture. Overall, the patterns are influenced by the acculturation of India, European, Japanese, Persian, 


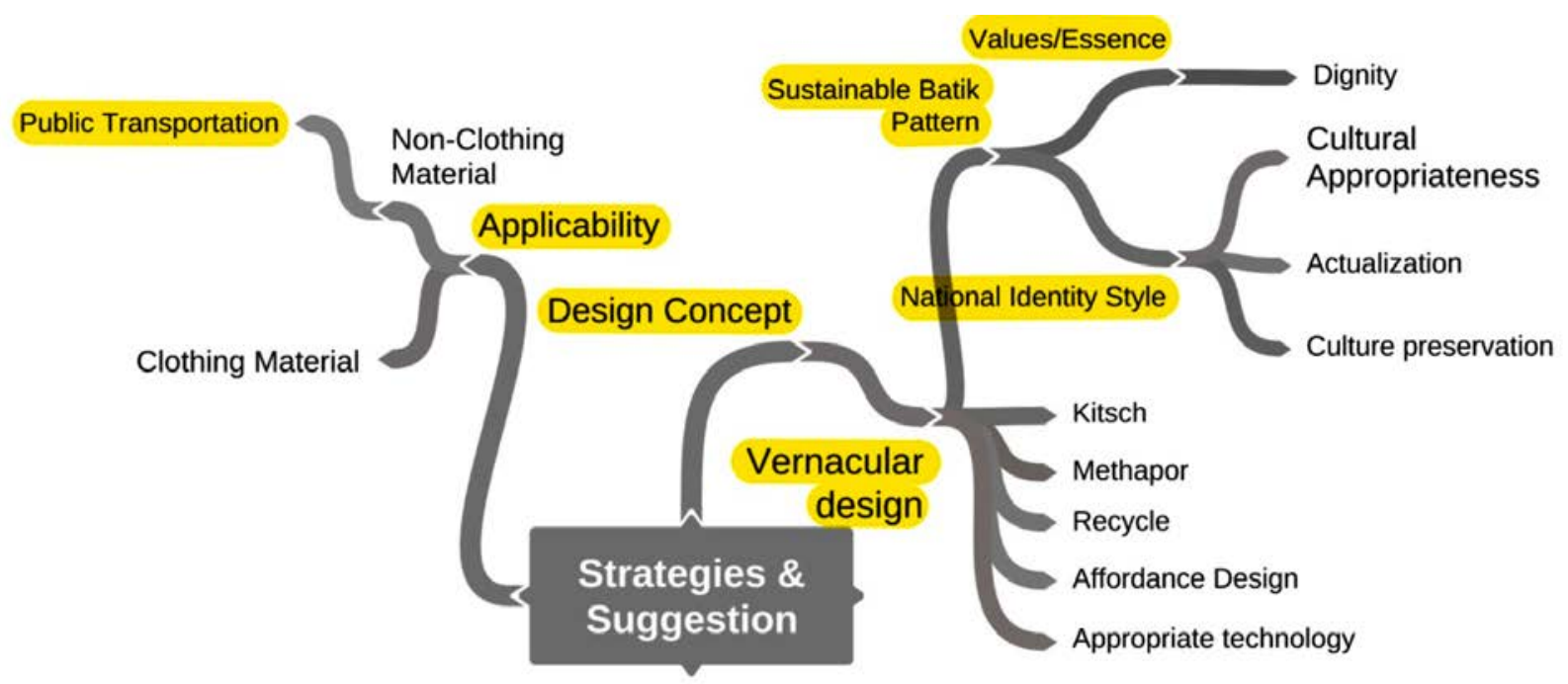

Figure 5. Mind map sustainable Batik as Indonesian vernacular design

and religions of Islam, Hindu, and Buddha. The motifs are mainly classified with geometrical shape, flora, fauna, and nature objects (e.g. rocks, sky, clouds, etc.). Through this study, Batik motifs were compared by its influences, founded, characteristics, meanings (values), and pattern images as shown in Table 1 and Figure 6.

\section{B. Applicability value to the public transportation equipment design}

Batik motifs feasibility as the design concept of public transportation equipment is necessary. It is considering that the development still depends on imports from overseas and the various positive implicit meanings from thousands of Batik motifs. The applicability of Batik needs to emphasize the suitable requirement, wise application, and consider the essence meanings for developing the public transportation equipment issue. Application Batik to public transportation equipment needs particular consideration in order that the motifs have a positive image and nationality reflection, high values, taste, historical track record, and artistic initiative. In the past, some Batik needs to conduct a particular ritual like soaking the fabrics for 40 days and nights intended or appealing the aura. Another special ritual was founded with fasting, ascetic, and many more. The suitable motif selection and color application adapt to the public transport and the equipment concept in order each pattern, lines, and dots of Batik motif implicit social hierarchy, hope and pray. Indonesia, which in developing public transportation equipment, needs to consider the concept of Batik motifs of rising, resurrection, nationalism, independent, distinctive area, rapid and hoping to the better future of sustainable transportation.

\section{Integrating batik application possibilities to sustainable transportation}

Product design synthetically applies science and technology to design and objects. To create products that will enjoy by most people, both functionality and modern aesthetics necessary to be considered by designers. Moreover uses their scientific techniques or personal artistic talents, but also combine them together and to be a fun design product that can be used. Modern product design intended to acquire the concept of traditional culture, social ideals, and laws of nature. Besides integrating with inward forms and functions, human coordinating system, engine, and environment.

Indonesia, as a developing country in South East Asia, has several public transportation system futures. Usually, the concept adopts rapid transportation technologies from abroad. The procedures are through government procurement of goods and services from abroad with the state budget. Product design offers an option to combine sciences, technology, function, innovate product form, structure, enhance cultural significance, and consuming taste to the new concept of contemporary design. In order, it's emphasized for most people with particular markets. Modern influence styles of other variances fabrics from abroad are one of a factor that leads to decreased interest in using Batik. Integrating Batik as the national identity culture onto those developments concept is a feasible challenge, in view of the transportation function to daily mobility.

Batik privileges have a lot of patterns, motifs, and different philosophical and historical values in almost every region, the distinctive blend of colors and how to create them make more value which other countries do not have. Batik is commonly used as a fashion application either traditional or modern contemporary yet rarely applications to another form such as public transport either vehicle or infrastructure.

Among urban transportation and mobility applications, Batik has wide motifs and meanings. The fields of social design place it as an alternative replacement for automotive fabrics and formalistic in aesthetics. It is an advantage to position the reinterpretation in regard to the effort to raise up interest and recognition of cultural identity factors. Inheriting Batik elements ideals are with applying Batik visual elements form in colors and graphs (imitating, decomposition, and reconstruction also 
Table 1.

The distribution mapping of Batik based on regional characteristics and substances

\begin{tabular}{|c|c|c|}
\hline & Description & $\begin{array}{l}\text { Pattern } \\
\text { image }\end{array}$ \\
\hline Pattern name & Kawung & \multirow{5}{*}{$\begin{array}{l}\text { Figure } \\
6(a)\end{array}$} \\
\hline Influence & Native Indonesia & \\
\hline Founded & Inland Mid Java & \\
\hline Characteristics & $\begin{array}{l}\text { - Earthy colours i.e. black, indigo, brown, and sogan (brown-yellow colour) generated from eco-friendly } \\
\text { natural colouring techniques. } \\
\text { Metaphor from Arenga pinnata fruit that has an oval shape with opaque white colour and others } \\
\text { believe from the shape of Kwangwung (Oryctes rhinoceros). }\end{array}$ & \\
\hline Meanings & Clean heart, useful for people, national unity and the Symbol of wise, wisdom, and self-control. & \\
\hline Pattern name & Parang & \multirow{5}{*}{$\begin{array}{l}\text { Figure } \\
6(\mathrm{~b})\end{array}$} \\
\hline Influence & Native Indonesia & \\
\hline Founded & Inland Mid Java , Mataram Kartasura (Solo City) & \\
\hline Characteristics & $\begin{array}{l}\text { - Identical with a group of slash motifs that are arranged with parallel lines of an oblique angle. } \\
\text { - The sustain arrangement like "S" letters taken from the metaphor of ocean waves. }\end{array}$ & \\
\hline Meanings & $\begin{array}{l}\text { A spirit that never extinct, efforts to improve and stand up for welfare and kinship. } \\
\text { - The straight diagonal line represents respect, ambition, and loyalty to the true value. } \\
\text { - The dynamics in this parang pattern are also called agility, alertness, and continuity between workers. }\end{array}$ & \\
\hline Pattern name & Paksi Naga Liman & \multirow{5}{*}{$\begin{array}{l}\text { Figure } \\
6(\mathrm{c})\end{array}$} \\
\hline Influence & Acculturation Indonesian with Persian, India and China with spreading religion of Islam, Hindu and Budha. & \\
\hline Founded & Coastal of West Javanese region (Cirebon City) & \\
\hline Characteristics & $\begin{array}{l}\text { This motif represents a sacred cart with three legendary hieratic animals, which are paksi (garuda bird), } \\
\text { naga (dragon), Iiman (elephant). }\end{array}$ & \\
\hline Meanings & $\begin{array}{l}\text { Whole glory sovereignty, bird as guardians of sovereignty in the air (jaya dirgantara), dragon as guardian of } \\
\text { sea sovereignty (jaya bahari) and elephant as a guardian of sovereignty on land (jayabhumi) }\end{array}$ & \\
\hline Pattern name & Hokokai & \multirow{5}{*}{$\begin{array}{l}\text { Figure } \\
6(d)\end{array}$} \\
\hline Influence & Acculturation Indonesian and Japanese & \\
\hline Founded & Coastal of Mid Javanese region (Pekalongan City) & \\
\hline Characteristics & $\begin{array}{l}\text { A vibrant colour like other coastal motifs made as an offering to the new ruler of that era by aligning the } \\
\text { motifs and ornaments made with Japanese taste. }\end{array}$ & \\
\hline Meanings & $\begin{array}{l}\text { Discipline or perfection in self-control. Remembering the grapple of Pekalongan Batik craftsmen Indonesia } \\
\text { was independent from Japan colonialism. }\end{array}$ & \\
\hline
\end{tabular}

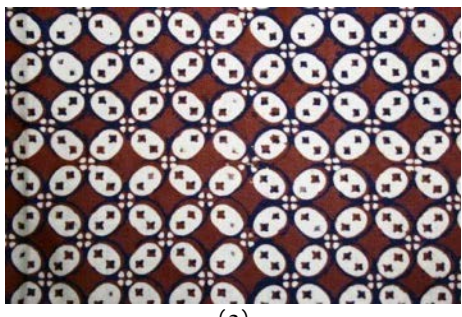

(a)

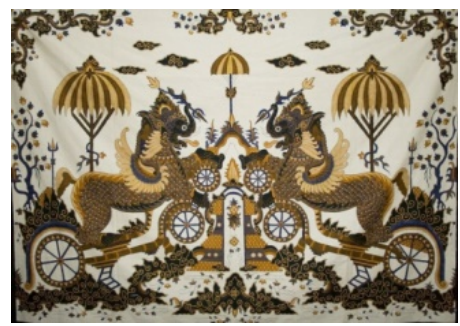

(c)

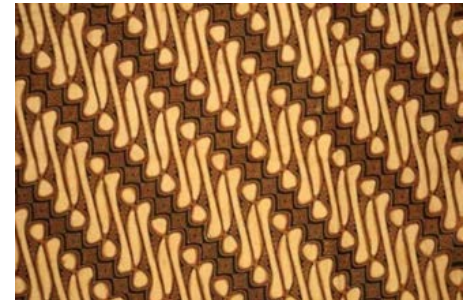

(b)

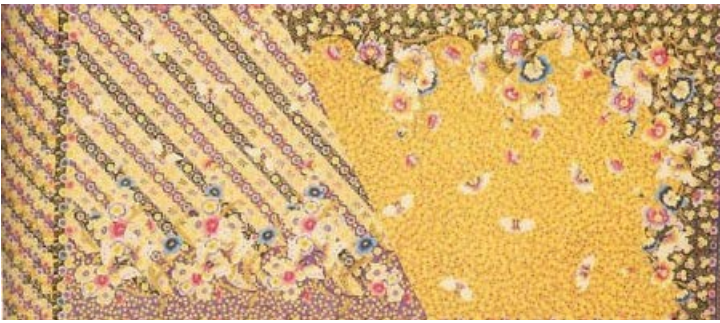

(d)

Figure 6. Batik pattern image; (a) Kawung; (b) Parang; (c) Paksi Naga Liman; and (d) Hokokai

digging principle) and lastly applying the structures. The meaning and theory of vernacular Batik as traditional elements will helpful for aesthetics research in modern product design.

D. Inheriting of Batik motifs, comprehension, and decomposing

One of Batik's producers in west java was in Cirebon city, as the origin of coastal Batik, the pattern was influenced by the location and as a harbor from the past. This city was merrier visited by trading activities from either local or international. The activities also generate new ideologies from multicultural effects; this city also one of the Islamic spreading centers in West Java. The characteristics are that using a bright color, asymmetrical, and drawn on plain media. The objects that simplified metaphor from the kingdom circumstances were plants, mythology animals, wings form, jewelry, and cloudy cloud. In every form were also implied particular meanings. 
The motifs and color decomposition and reconstruction were a connector method to integrate forming that is usually used in modern designing. It was evolved the elements of a new form that generate from basic comprehension of original motifs. Colors decomposition as for the redesigning of traditional colors in public transportation equipment, the designer needs to analyze the characteristics, function, principal, and role of the colors, composition, and forms of vernacular Batik.

"Mega mendung" or cloudy cloud with darken sky become raining is the motif with clouds pattern has a meaning and deep philosophy. The message contains a desire for patient attitude and cooling down circumstances with seven gradations from dark into light blue. Wide cloud and overcast are elements also mean to illustrate the Cirebon palace shade or protecting their people. As stated before that this motif was affected by multicultural activities in the past; the differences with Chinese cloud patterns are more sharp lines and presenting gradation colors, as shown in Figure 7.

\section{E. Reinterpretation to contemporary public \\ transportation equipment design concepts}

The product design process is generating ideas and developing into a final product to be consumed. The approach adopted in this complex problem is based on the design for affordability. Designers should consider systems, services, and products in relation to what they should do, how they should behave, what they look like, and whether they will be understood by the users in the manner intended. The starting point for solving a problem springs from an idea developed in mind. A detailed exploration of the idea is vital to take it from the intangible to the tangible, along with the ability to articulate the idea to others.

A carriage for the Queen palace called jempana, or in term of local language jemjeming prana which means loyalty or jemjeming pengagem manahayang which means the persistence of heart. At the top of the throne is a kind of metal umbrella decorated with mega mendung motifs, element sizing the human soul that can protect individuals, families, relatives, and society. This Batik motif has been applied to the transportation system in the year 1428 , as shown in Figure 8.

An integrating as contemporary design today will have a different appearance and feels, in other words the design will ever-changing due to the past, today, and future developments such as technology, material, etc. It is always evolving and easily adapt

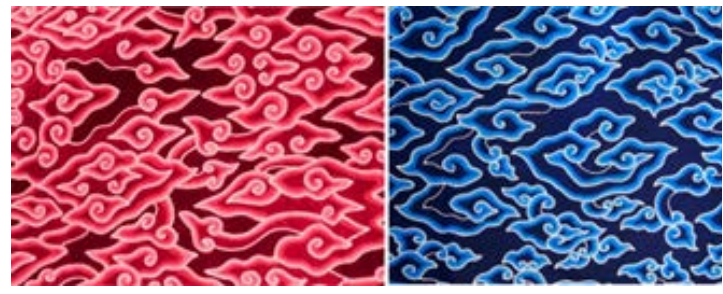

Figure 7. Mega mendung or cloudy cloud is the brilliant colours of coastal Batik vibrant colours, non-geometric (organics) shape, natural motifs and influenced from wide acculturation of maritime and trading culture mostly from Chinese

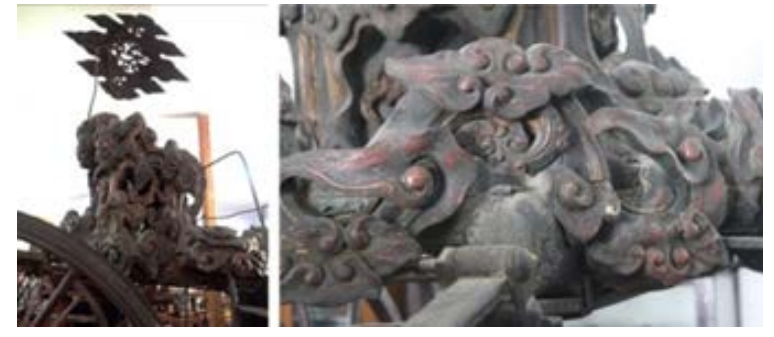

Figure 8. Batik application in the past was applied to Kereta Jempana traditional four wheels carrier

the other styles and values like Batik vernacular elements concept. The concept of autonomous electric vehicles by Honda was called NeuV. It is equipped with artificial intelligence, a full-touch panel interface, and two seats capacity. The headlight concept wants to present an organic line, something floating like the tail of clouds. It is also proof that reinterpretation of a metaphor concept like Batik Mega mendung and possible to conduct even to other parts of vehicles either interior or exterior, whether explicit or implicit as shown in Figure 9.

\section{F. The applicability of vernacular indonesian technique and material}

Every country has various distinctive production techniques to supports the products. The characteristic of vernacular design shows the dependency of skill, experience, and talent obtained by hereditary. Many peoples use an indigenous technique with natural materials while the others adopt modern with non-natural materials or combined of both. Usually, the technical process could be applied to materials of stones, natural or artificial fibers, leather, rattan, bamboo, wood, metals (gold, silver, copper, bronze, and iron), wood, glass, porcelain, fabric, marble, and clay.

Batik, as an indigenous motif represents Indonesian culture, necessarily to discover the applicability of the motifs in vernacular material and production. Firstly, the possible material to be applied in public transport is leather that is produced with various scales from handicraft to heavy industry. Leather has a durable and flexible characteristic created with tanning animal rawhides. Mainly this material used as clothing, shoes, coat, and fashion accessories nevertheless as well as applied for musical instruments supports. The leather carving method founded in Indonesia was applied as a shadow puppet material called wayang kulit that mainly founded in Central Java and East

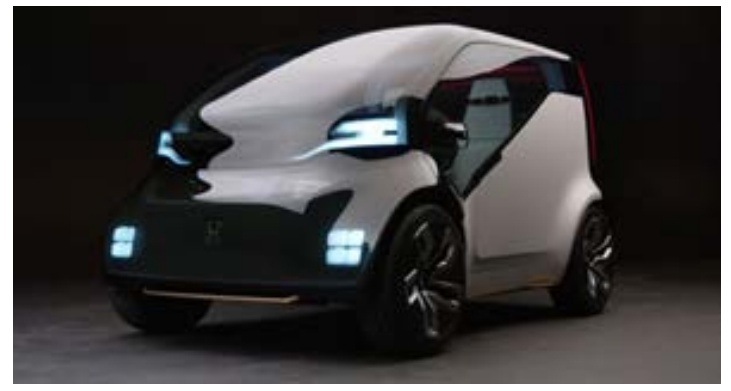

Figure 9. Headlight concept of Honda NeuV 


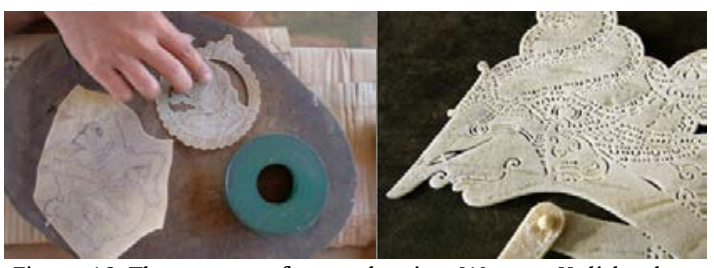

Figure 10. The process of pre-colouring Wayang Kulit leather

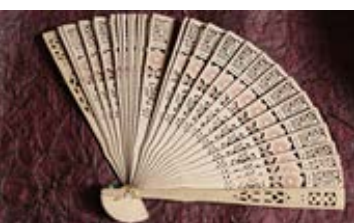

(a)

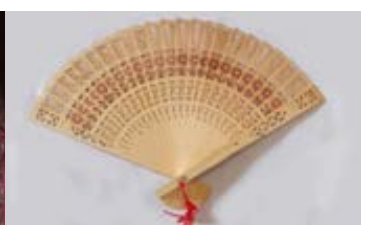

(b)
Figure 11. handheld fan: (a) Chinese hand fan; (b) Indonesian cendana hand fan.

Java. This puppet played at night with narration and traditional music with screen and lighting, allowing the audiences to watch only the shadow or from the puppeteer side. Wayang kulit was also approved by UNESCO in 2003 as (Masterpiece of Oral and Intangible Heritage of Humanity) usually used as a tool for spreading thought, education, science, and information. Made from cattle, cow, buffalo, or ox leather with a particular preparation before it is carved. In contrast, this preparation makes the leather rigidly, translucent, easy to carving, transparent also long-lasting material as shown in Figure 10.

Moreover, this shadow puppet believes are brought to Indonesia from the trading activity of India spreading the Hindustan religion. Showed the similarities of the shadow puppet show, founded in Andra Pradesh India called tholu bommalata with typical leather differences of animals skin material, story show content, puppet character, musical instrument, and motifs. Some puppets are made from more than one type of skin instead of a cow considering religion issues in India; these are antelope, spotted deer, and goat. This shadow puppet also founded in some countries like Cambodia, Thailand, Malaysia, Chinese, Taiwan, Italy, and Australia, with each typical characteristic.

One of the Indonesian woodcraft is an engraved handheld folding fan made from Cendana tree/sandalwood that was founded in Nusa Tenggara, Indonesia. Recently, it is often used as a dance performance equipment and souvenir from Indonesia. Cendana derived from a Sanskrit term in Latin is called Santalum album $L$. include to Santalaceae family. Instead of furniture function, sandalwood is often used as carving material, keris (ceremonial knife) and generates oil for herbal medicine, aromatherapy, antiseptic, antimicrobial, cosmetics and gives a luxury impression. While others believe as an alternative medicine to bring people closer to God. The base oil of sandalwood, which is very expensive in its pure form, is used primarily for healing the Ayurveda way and to relieve anxiety. Moreover, folded handheld fans are popular in Europe during the eighteen century. Various material combinations are applied such as gold, tortoiseshell, ivory, mother-of-pearl, horn, or wood. Other countries also have this type of handheld fan, which is Chinese and Japan as shown in Figure 11.

The acculturation in the past, especially overseas trading activity in Indonesia generates a particular culture and craftsmanship. As time goes by, modern cultures assumed affecting the interest of local culture. At the time, millennials should develop the preservation of cultural heritage along with modern life. In order, the workmanship difficulties and knowledge transfer as the factor this issue and the culture become faded even extinct. Applicability of the traditional material into the indigenous pattern such as Batik will generate the identity mark of Indonesia luxurious. The results hopefully, will encourage sustainable culture and preservation.

\section{Conclusion}

A study has been conducted to solve the identity design problem in public transportation equipment development in Indonesia. The values of Batik were gathered, assessed, and proved that contains geographic of origin, the essences, and characteristics to be applied as design element strategies. We found the regional identity of the historical, local wisdom essence, acculturation, various colors, and original shapes of the Batik motifs. Moreover, Indonesian fancy design is also supported by other possibilities indigenous material and technique that usually used, particularly in Indonesia. These possibilities were identically Indonesian and also applicable as the sustainable public transport equipment design identity issue solution. Advanced technology should evolve not to resist along with the indigenous lifestyle to conserve it. Public transportation equipment development concept for daily mobility activities and tourism played a role as feasible media to apply the vernacular Batik concept to expose the national cultural identity. This design approach can bring significant values of cultural values, market values, and social values. At the same time, as the universal culture elements, the product can transmit traditionally and advanced culture and create a fashionable new culture, and bring the cultural values to people. Culture always spreads with the product and then can be understood and accepted. Thus, the product can show commonalty consuming concepts, people's values expecting about future lifestyle and up-to-date ideology. By applying the vernacular element in modern product design, it is useful to define product functions, innovative product form, and structure and to enhance the cultural significance and consuming taste, carve out a new market. The application of traditional cultural symbols in modern product design helps to explore new methods and enrich up-to-date design culture.

\section{Declarations}

\section{Author contribution}

Y.M.K Sya ' bana and G.B Park contributed equally as the main contributor of this paper. All authors read and approved the final paper. 


\section{Funding statement}

This research did not receive any specific grant from funding agencies in the public, commercial, or not-forprofit sectors.

\section{Conflict of interest}

The authors declare no conflict of interest.

\section{Additional information}

No additional information is available for this paper.

\section{References}

[1] S. Sutia, S. Adha, and M. Fahlevi, "Why do customers intend to repurchase transportation online in Indonesia?," E3S Web Conf., vol. 125, no. 201 9, pp. 9-13, 2019.

[2] Badan Pusat Statistik, "Stastika transportasi DKI Jakarta," 2015.

[3] S. Soehodho, "Public Transportation Development and Traffic Accident Prevention in Indonesia," IATSS Res., vol. 40, no. 2, pp. 76-80, 2017.

[4] Indonesia-Investments, "Automotive manufacturing industry Indonesia," 2017.

[5] Y. Shao, E. Lange, K. Thwaites, and L. Binyi, "Defining local identity," Landsc. Archit. Front., vol. 5, no. 51678417, pp. 24 41, 2017.

[6] A. Winchenbach, P. Hanna, and G. Miller, "Rethinking decent work: the value of dignity in tourism employment," J. Sustain. Tour., vol. 27, no. 7, pp. 1026-1043, 2019.

[7] R. P. Canaan, "Creative economy and cultural heritage: A proposal to tourism development and appreciation of local identity," Strateg. Des. Res. J., vol. 12, no. 2, pp. 276-288, 2019.

[8] S. Z. Abidin, A. Othman, Z. Shamsuddin, Z. Samsudin, H. Hassan, and W. A. W. Mohamed, "Malaysian product design identity: issues, transformation, and challenges," in Proceedings of the 2nd International Colloquium of Art and Design Education Research (i-CADER 2015), Singapore: Springer Singapore, 2016 pp. 305-318.

[9] A. Rahma, J. Jaenudin, and A. Marifatullah, "Living a multicultural lifestyle with Batik: identity, representation, significance," in International Conference on Culture and Language in Southeast Asia (ICCLAS 2017), 2018, vol. 154, no. Icclas 2017, pp. 203-205.

[10] Beritagar.id, "Indonesia punya 5.849 motif Batik," 2015

[11] N. Tresnawati, I. Saleh, Sudarmin, and S. Wardani, "Scientific reconstruction of local plants as the basic materials of Batik natural dyes," J. Phys. Conf. Ser., vol. 1511, no. 1, 2020.

[12] M. T. Nawawi and R. Rodhiah, "SWOT Analysis on the SMEs of Batik products in Jambi city," 8th Int. Conf. Entrep. Bus. Manag. Untar (ICEBM 2019), vol. 145, no. Icebm 2019, pp. 356-360, 2020

[13] J. Mao et al., "Application of emotional design to the form redesign of a midwifery training aid," KnE Eng., vol. 2, no. 2, p. 44, 2017.

[14] E. Shrestha, "Vernacular architecture in contemporary context in the outskirts of Kathmandu valley," B.S. Thesis, Sch. of Education., Kathmandu University, pp. 1-18, 2019, [Online]. Available.

[15] J. Al-Qawasmi, "Vernacular as a renewable resource: toward region-specific architecture in Saudi Arabia, a case from KFUPM," Archit. Eng. Des. Manag., vol. 12, no. 2, pp. 81-96, 2016.

[16] S. T. F. Poon, "Contribution of ecological design to critical regionalism: analysing sustainability effectiveness in vernacular urban building," ISPRS Ann. Photogramm. Remote Sens. Spat. Inf. Sci. vol. 4, no. 4/W9, pp. 103-109, 2019.

[17] T. Chotpradit et al., "Terminologies of 'Modern' and 'Contemporary' 'Art' in southeast asia's vernacular languages: Indonesian, Javanese, Khmer, Lao, Malay, Myanmar/Burmese, Tagalog/Filipino, Thai and Vietnamese," Southeast Now Dir. Contemp. Mod. Art Asia, vol. 2, no. 2, pp. 65-95, 2018.

[18] C. C. C. Stefan A. Ortlieb, "Kitsch and perception: towards a new 'aesthetic from below,' " Art Percept., vol. 7, no. 1, pp. 126, 2019.

[19] G. Tedman, "Origins of Kitsch," Rethink. Marx., vol. 22, no. 1, pp. 56-67, 2010.

[20] M. Kjellman-Chapin, "The politics of Kitsch," Rethink. Marx., vol. 22, no. 1, pp. 27-41, 2010
[21] C. Greenberg, "Avant-Garde and Kitsch," A Hist. West. Art Mark., pp. 24-27, 2020.

[22] I. Ratnawati, Triyanto, and Syakir, "Meanings possessed by gajah oling Batik in seblang rituals performed by osing tribe in Banyuwangi," Int. J. Recent Technol. Eng., vol. 8, no. 2 Special Issue 9, pp. 183-186, 2019.

[23] P. Nimas Ayu, N. A. Pramesti, H. Pamadhi, and A. Garbo, "Local wisdom values in Kawung Batik and its relevance to moral education," in Proceedings of the International Conference on Art and Arts Education (ICAAE 2018), 2019, vol. 327, no. Icaae 2018, pp. 178-182.

[24] Y. Mustaqim and K. Sya, "The applicability of sustainable design values on electric bike sharing concept in Indonesia," 2019 Int. Conf. Sustain. Energy Eng. Appl., pp. 125-130, 2019.

[25] D. Widiawati, "The utilization of Batik pattern and natura dyes as valuation of the local value fan Batik society," Sosioteknologi(Sostek), pp. 5-7, 2018.

[26] A. Alamsyah, S. Maziyah, and A. Supriyono, "Natural coloring as a coloring material for Batik craft in Jepara," in Proceedings of the 4th International Conference on Indonesian Social and Political Enquiries, ICISPE 2019, 2020, pp. 1-8.

[27] L. Magnier, R. Mugge, and J. Schoormans, "Turning ocean garbage into products - consumers' evaluations of products made of recycled ocean plastic," J. Clean. Prod., vol. 215, pp. 84-98, 2019

[28] J. Shi, Q. Li, H. Li, S. Li, J. Zhang, and Y. Shi, "Eco-design for recycled products: rejuvenating mullite from coal fly ash," Resour. Conserv. Recycl., vol. 124, no. December 2016, pp. 6773, 2017.

[29] S. K. Venkatachary, R. Samikannu, S. Murugesan, N. R. Dasari, and R. U. Subramaniyam, "Economics and impact of recycling solar waste materials on the environment and health care," Environ. Technol. Innov., vol. 20, p. 101130, 2020.

[30] L. W. Zhang, A. O. Sojobi, V. K. R. Kodur, and K. M. Liew, "Effective utilization and recycling of mixed recycled aggregates for a greener environment," J. Clean. Prod., vol. 236 p. 117600,2019 .

[31] H. Li and K. Englund, "Recycling of carbon fiber-reinforced thermoplastic composite wastes from the aerospace industry," J. Compos. Mater., vol. 51, no. 9, pp. 1265-1273, 2017.

[32] A. Mayyas, D. Steward, and M. Mann, "The case for recycling: Overview and challenges in the material supply chain for automotive li-ion batteries," Sustain. Mater. Technol., vol. 19, p. e00087, 2019.

[33] G. Harper et al., "Recycling lithium-ion batteries from electric vehicles," Nature, vol. 575, no. 7781, pp. 75-86, 2019.

[34] H. Shin, J. Hwang, and H. Kim, "Appropriate technology for grassroots innovation in developing countries for sustainable development: The case of Laos," J. Clean. Prod., vol. 232, pp. $1167-1175,2019$

[35] D. Okoye, "Appropriate technology and income differences," Int. Econ. Rev. (Philadelphia)., vol. 57, no. 3, pp. 955-996, 2016.

[36] D. Musunuri, "Appropriate technology and economic development of emerging economies - a myth or a reality," $\mathrm{J}$. Technol. Manag. Grow. Econ., vol. 5, no. 1, pp. 51-62, 2014.

[37] S. Moussawi, "User experiences with personal intelligent agents," in Proceedings of the 2018 ACM SIGMIS Conference on Computers and People Research, pp. 86-92, 2018.

[38] J. Haase, K. P. Wiedmann, and J. Bettels, "Sensory imagery in advertising: how the senses affect perceived product design and consumer attitude," J. Mark. Commun., vol. 26, no. 5, pp. 475-487, 2020.

[39] H. Jung, H. Wiltse, M. Wiberg, and E. Stolterman, "Metaphors, materialities, and affordances: hybrid morphologies in the design of interactive artifacts," Des. Stud., vol. 53, pp. 24-46, 2017.

[40] L. H. Chen and Y. C. Liu, "Affordance and intuitive interface design for elder users with dementia," Procedia CIRP, vol. 60, pp. $470-475,2017$

[41] C. Y. Tsai, "Effect of graphic simplification and graphic metaphor on the memory and identification of travel map signs running head," Int. J. Ind. Ergon., vol. 61, pp. 29-36, 2017.

[42] M. K. Rasmussen, G. M. Troiano, M. G. Petersen, J. G. Simonsen, and K. Hornbæk, "The new thinking in emotional use experience: from visual metaphor to interactive affordance," Conf. Hum. Factors Comput. Syst. - Proc., pp. 490-497, 2016.

[43] S. Y. Kim and E. McFadden, "Using established ux design techniques and visual enhancements to redesign an enterprise mobile app and improve employee productivity and engagement," in Advances in Intelligent Systems and Computing, vol. 972, pp. 169-176, 2020. 